\title{
Electrical Properties of Porous Silicon as a Biosensor Material
}

\author{
Kristina A. Ganichkina* and Natalia V. Latukhina
}

Department of Solid State Physics and Nonequilibrium Systems, Samara National Research University, 34 Moskovskoe shosse, Samara 443086, Russian Federation

* e-mail: ganichkina.k@mail.ru

\begin{abstract}
The electrical properties of porous silicon nanocomposites with various glucose solutions were studied. The current-voltage characteristics (I-V) of glucose solutions in water and tear fluid, as well as porous silicon samples of various porosities saturated with these solutions were measured. The porosity and glucose content in the pores were determined by the gravimetric method. Measurements of the I-V characteristics and photoconductivity of nanocomposites showed that their electrical conductivity appreciably depends on the glucose content in solutions. (C) 2020 Journal of Biomedical Photonics \& Engineering.
\end{abstract}

Keywords: glucose; porous silicon; PC; por-Si; nanocomposite; biosensor; CVC; photoconductivity.

Paper \#3348 received 17 Jan 2020; revised manuscript received 11 Mar 2020; accepted for publication 11 Mar 2020; published online 26 Mar 2020. doi: 10.18287/JBPE20.06.010306.

\section{Introduction}

The problem of the choice of material for creating biosensors is relevant today. New materials are still being researched for use as a sensitive layer. It is important to solve such problems as a high sensitivity of the material to the studied object, selectivity, nontoxicity of biomaterial, biocompatibility. Porous silicon is a promising material for the creation of biosensors. Due to the developed surface of porous silicon, it can be used as a biosensitive layer [1, 2].

The widespread use of porous silicon for medical purposes makes the problem of the dependence of the physicochemical properties of nanocomposites based on porous silicon on their structure and composition very urgent. Thus, the development of methods for studying these properties is important.

When creating biosensors on porous silicon, it is promising to use its electrical properties. The electrical properties of porous silicon are highly dependent on substances trapped in the pores $[6,7]$. This is primarily due to the presence of nanocrystals on the pore walls, the electronic structure of which is very sensitive to the presence of impurities in the pores. Hence, this is a possibility of detecting substances by changing the electrical properties of porous silicon [8].

In this paper, we studied the dependence of the electrical conductivity of porous silicon on the content of glucose solutions in it with different concentrations of matter. The choice of glucose as a test substance is due to the relevance of improving methods for analyzing blood glucose levels. This analysis is very important for people with diabetes. It is important for a person suffering from diabetes to know the level of glucose for control, diet and drug treatment [1].

\section{Experimental and Calculation Methods}

\subsection{Sample manufacturing procedure}

Samples of porous silicon were prepared by electrochemical etching in a fluorine-containing solution. The composition of the electrolyte: water, isopropyl alcohol, hydrofluoric acid in a ratio of 6:9:5: $\mathrm{H}_{2} \mathrm{O}+\left(\mathrm{CH}_{3}\right)_{2} \mathrm{CHOH}+\mathrm{HF}$.

Etching occurred at currents of $60 \mathrm{~mA}, 80 \mathrm{~mA}$ and lasted for 15, 20 and $30 \mathrm{~min}$ (Fig 1). Porosity was determined by the gravimetric method from the decrease in sample weight after etching. Depending on the etching conditions, the porosity varied from $17 \%$ to $43 \%$. Italics show the values of porosity calculated for other samples made by similar methods. The accuracy of the calculation of porosity by the gravimetric method is determined by the accuracy of weighing and determining the geometric parameters of the porous 
Table 1 Samples and etching conditions.

\begin{tabular}{|c|c|c|c|c|}
\hline \multirow{2}{*}{ Sample \# } & \multirow{2}{*}{ Surface type } & \multicolumn{2}{|c|}{ Etching mode } & \multirow{2}{*}{$\begin{array}{c}\text { Porosity, \% } \\
\text { (expected) }\end{array}$} \\
\hline & & $\mathrm{I}, \mathrm{mA}$ & Etching time, $\min$ & \\
\hline $\mathrm{Y}$ & Polished surface & 80 & 15 & 17 \\
\hline $\mathrm{O}$ & Polished surface & 80 & 10 & 17 \\
\hline $\mathrm{U}$ & Polished surface & 80 & 20 & 17 \\
\hline $\mathrm{G}$ & Polished surface & 60 & 20 & $\overline{17}$ \\
\hline $\mathrm{X}$ & Polished surface & 80 & 30 & 22 \\
\hline$E$ & Polished surface & 60 & 30 & 34 \\
\hline $\mathrm{R}$ & Polished surface & 80 & 30 & 34 \\
\hline $\mathrm{A}$ & Polished surface & 60 & 20 & 17 \\
\hline $\mathrm{K}$ & Textured surface & 80 & 30 & $\overline{37}$ \\
\hline $\mathrm{P}$ & Textured surface & 80 & 15 & 21 \\
\hline $\mathrm{Z}$ & Textured surface & 60 & 20 & 21 \\
\hline $\mathrm{L}$ & Textured surface & 80 & 20 & 21 \\
\hline $\mathrm{H}$ & Textured surface & 60 & 15 & 21 \\
\hline №1 & Textured surface & 60 & 10 & 21 \\
\hline №2 & Textured surface & 60 & 30 & 37 \\
\hline $\mathrm{J}$ & Ground surface & 80 & 20 & $\underline{43}$ \\
\hline $\mathrm{N}$ & Ground surface & 60 & 20 & 43 \\
\hline
\end{tabular}

layer and does not exceed $0.3 \%$, however, the difference in the values of porosity of identical samples reaches units of percent that is explained by the influence of uncontrolled factors of the etching process [3]. Therefore, the numerical values of porosity shown in Table 1 are estimated. Nevertheless, from an analysis of these data, it can be concluded that the samples with a polished surface have the maximum porosity (43\%); therefore, they are most promising for creating a biosensor.

To create nanocomposites with porous silicon, substances such as glucose and saline were used to understand how the properties of the material change when these substances are present in the pores because both substances are present in human blood and plasma in a noticeable amount. Solutions of glucose in the lacrimal fluid were also investigated because a number of researchers propose a method for determining the sugar content in human blood by the study of tears.

On samples $\mathrm{X}, \mathrm{O}, \mathrm{G}$ (polished surface); L, K (textured surface) and $\mathrm{N}$ (ground surface) and discrete contacts were applied through a mask with a conductive paste, and the I-V characteristics were measured on three parts of the sample: porous silicon, part with a glucose solution of different concentrations in water, part with a glucose solution of different concentrations in lacrimal fluid. Previous studies of the IR spectra of nanocomposites showed that the porous layer can be saturated with glucose from aqueous solutions [4].

\subsection{Measurement of photoconductivity and CVC}

A stand to measure photoconductivity and currentvoltage characteristics (Fig. 1) was used.

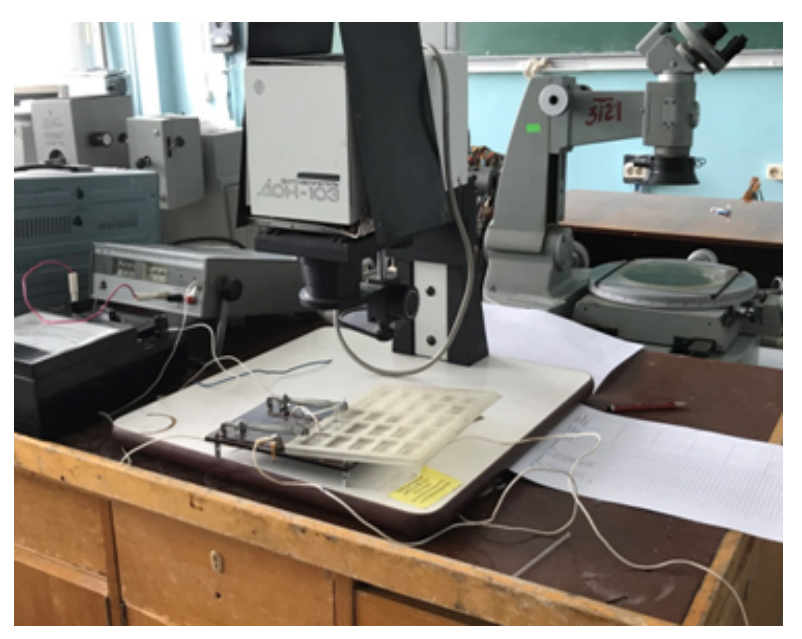

Fig. 1 Stand for measuring the current-voltage characteristic.

In this paper, to measure the dark current, the sample was fixed on a special holder and placed in a lightproof casing. To record the light characteristics, the sample was illuminated with a lamp. The current flowing through the sample was measured with a V7-21A universal voltmeter. A stabilized voltage was also supplied from the B5-43 power source. The voltage was measured with a V7-26 universal voltmeter; its measurement accuracy was $0.1 \mathrm{mV}$.

The resistance of the samples was calculated by measuring the voltage and current flowing through the sample.

To calculate the resistivity and conductivity, we use the formulas: 


$$
\begin{aligned}
& \rho=\frac{R \times d \times h}{L}, \\
& \sigma=\frac{1}{\rho^{\prime}}
\end{aligned}
$$

where $R$ - the resistance, $d$ - the thickness of the plate, we take it equal to $1, L-$ the distance between the contacts, $h$ - contact length (Fig. 2).

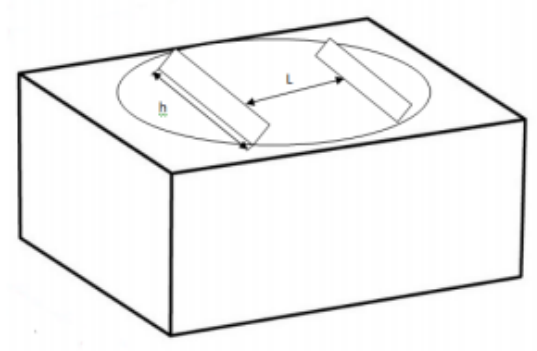

Fig. 2 Scheme for calculating the resistivity.

To measure the I-V characteristics, solutions of glucose in water containing $1 \%, 2 \%, 3 \%$, and $4 \%$ of the substance were prepared, and glucose solutions in the Slezin pharmacy preparation containing 3\%,6\%, and $12 \%$ glucose. Then, the current-voltage characteristics were measured and the electrical resistances of glucose, silicon, and then glucose together with silicon were calculated, and the relative measurement error $\Delta R / R$ was also calculated.

(a)
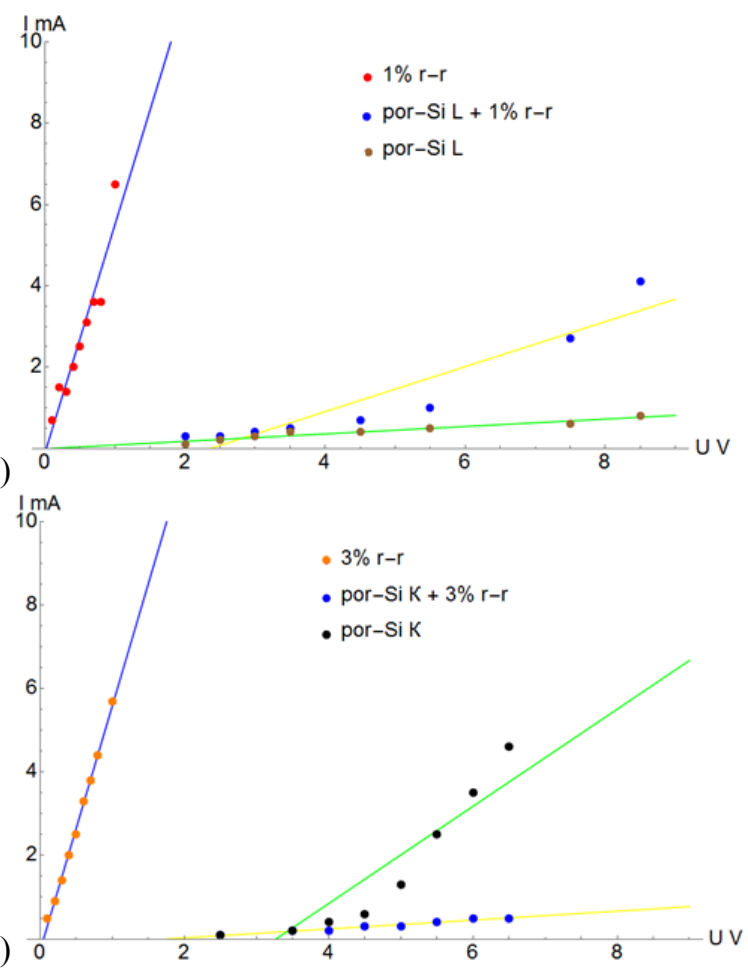

Researchers Yihao Chen, Siyuan Lu et al. developed the biosensor as a "two-electrode system" (working electrode and counter electrode) in measurements in vivo. A clinical study was conducted in vivo by examining the presence of glucose in tissue fluid. The work presents the electrochemical and mechanical characteristics of the device, as well as the amperometric I-t result recorded by a biosensor attached to the skin surface [5].

\section{Results}

Based on the experiment, the $\mathrm{I}-\mathrm{V}$ curves of the samples were constructed in the absence and presence of glucose (Fig. 3). The figures show graphs for a glucose solution ( $1 \%$ glucose solution in water), for a porous silicon wafer (por-Si) and for a nanocomposite (por-Si and an aqueous glucose solution of various concentrations).

It can be seen from the graphs in Fig. 3 for the most part, the dependence of current on voltage is linear in nature that allows us to use these data to calculate the resistance.

According to the results of measurements and calculations, a final Table 2 was compiled of the dependence of the resistance of the PC samples on the glucose content in them.

Based on the results, a graph of the dependence of the sample resistance on the percentage glucose in the solution was constructed (Fig. 4).

(b)

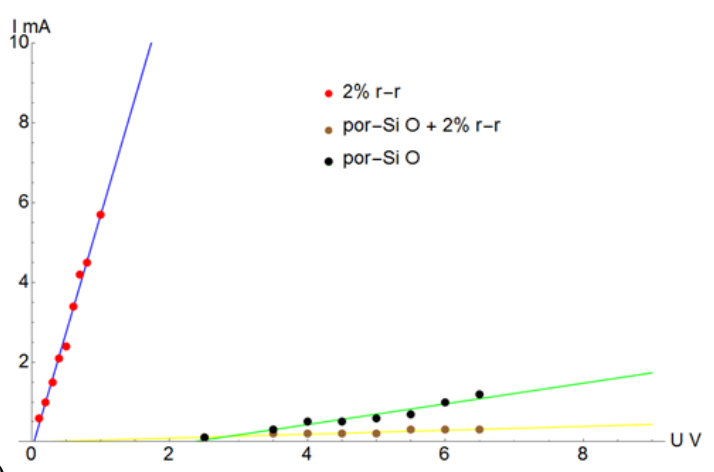

(d)

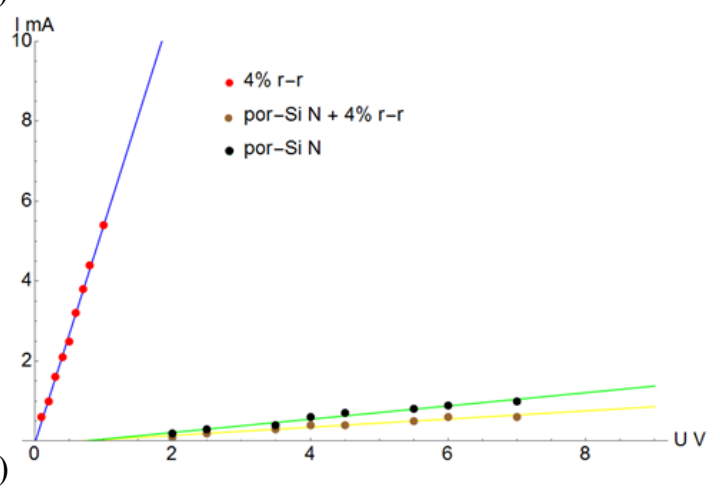

Fig. 3 CVC of the studied samples: (a) $1 \%$, (b) $2 \%$, (c) $3 \%$, (d) $4 \%$ glucose. 
Table 2 Dependence of the resistance of PC samples on glucose content.

\begin{tabular}{ccccccc}
$\begin{array}{c}\text { Sample } \\
\text { number and } \\
\text { glucose } \\
\text { concentration }\end{array}$ & $\begin{array}{c}\mathrm{R} \text { glucose, } \\
\mathrm{kOhm}\end{array}$ & $\begin{array}{c}\Delta \mathrm{R} / \mathrm{R} \text { glucose, } \\
\%\end{array}$ & $\begin{array}{c}\mathrm{R} \text { por-Si, } \\
\mathrm{kOhm}\end{array}$ & $\begin{array}{c}\Delta \mathrm{R} / \mathrm{R} \text { por-Si, } \\
\%\end{array}$ & $\begin{array}{c}\mathrm{R} \text { glucose } \\
+ \text { por-Si, } \\
\mathrm{kOhm}\end{array}$ & $\begin{array}{c}\Delta \mathrm{R} / \mathrm{R} \text { glucose } \\
+ \text { por-Si, } \\
\%\end{array}$ \\
\hline $\mathrm{L}(1 \%)$ & 178.4 & 3.4 & 13222.5 & 14 & 4285.7 & 1.9 \\
\hline $\mathrm{O}(2 \%)$ & 181.7 & 1.5 & 10552.5 & 7.2 & 6431.2 & 17.4 \\
\hline $\mathrm{K}(3 \%)$ & 191.4 & 3.6 & 12756.2 & 11 & 1728.2 & 1.6 \\
\hline $\mathrm{N}(4 \%)$ & 186.8 & 1.2 & 8737.5 & 9.1 & 1209.1 & 22.6
\end{tabular}

As can be seen from the graph in Fig. 4, the resistance of the nanocomposite significantly depends on the concentration of glucose in the solution.

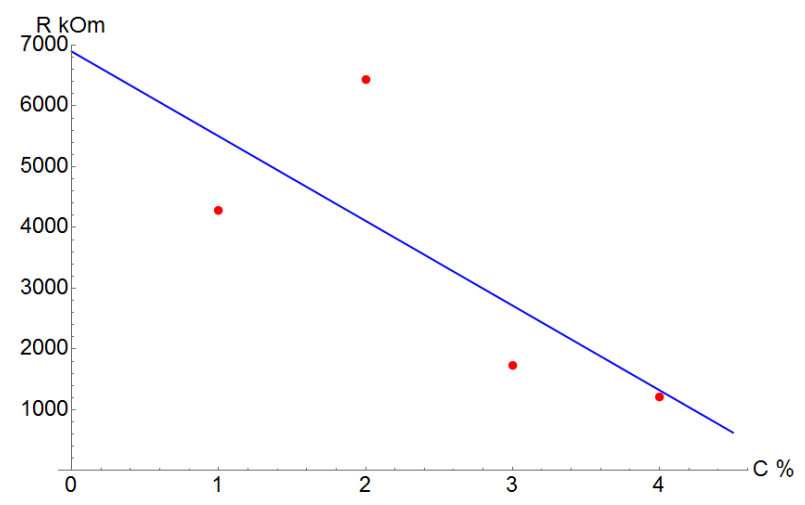

Fig. 4 The dependence of the silicon nanocomposite + glucose resistance on the percentage of glucose in the solution.

The next series of studies was related to measuring the dependence of the resistance of a silicon + glucose nanocomposite on the percentage of glucose in the tear fluid (3\%, $6 \%$, and $12 \%$ glucose). Porous silicon, on which nothing was applied, was taken as a control sample. The figures show graphs separately for the por-Si nanocomposite + glucose solution with the addition of a tear ( $1 \%$ glucose solution in a tear), for a porous silicon wafer (por-Si) and for a nanocomposite (por-Si and an aqueous glucose solution of various concentrations).

A porous silicon sample with added solutions of various concentrations was used. Also, according to the results, a graph of the dependence of the resistance of the silicon + glucose nanocomposite on the percentage of glucose in the solution was built. Based on the results of measurements and calculations, a final Table 3 of the dependence of the resistance of PC samples on the presence of a certain amount of glucose in them was compiled.

Figs. 5 and 6 show the $\mathrm{I}-\mathrm{V}$ characteristics and the dependence of resistance, measured and calculated similarly to the previous ones (Figs. 3-4).

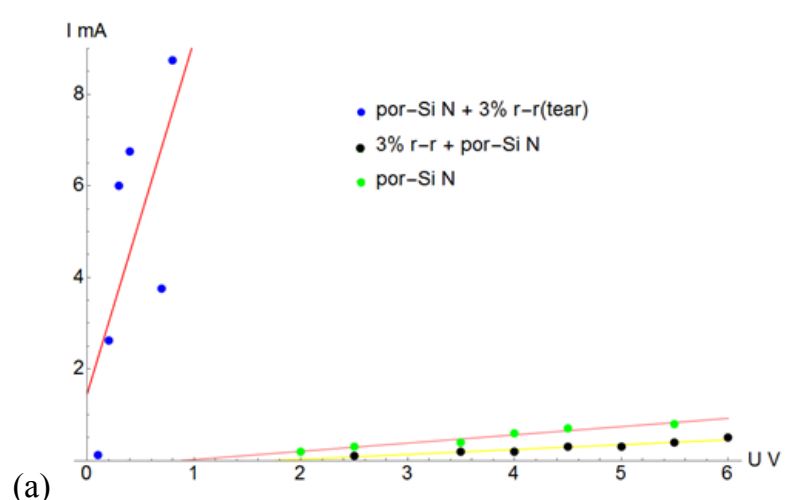

(a)

(b)

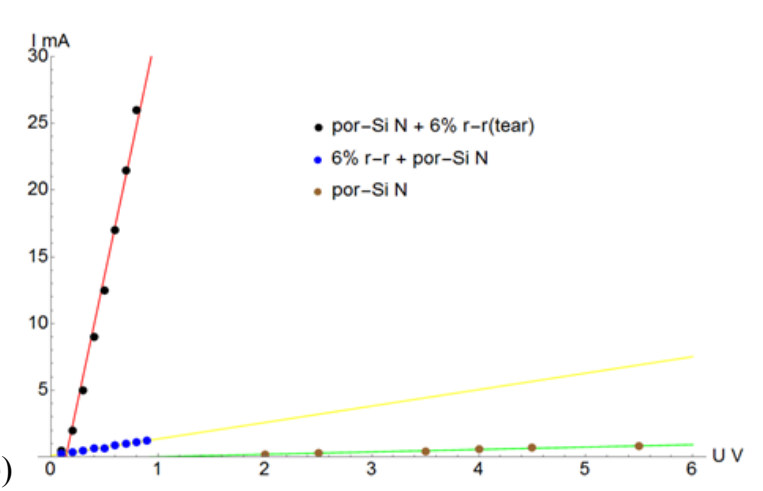

(c)

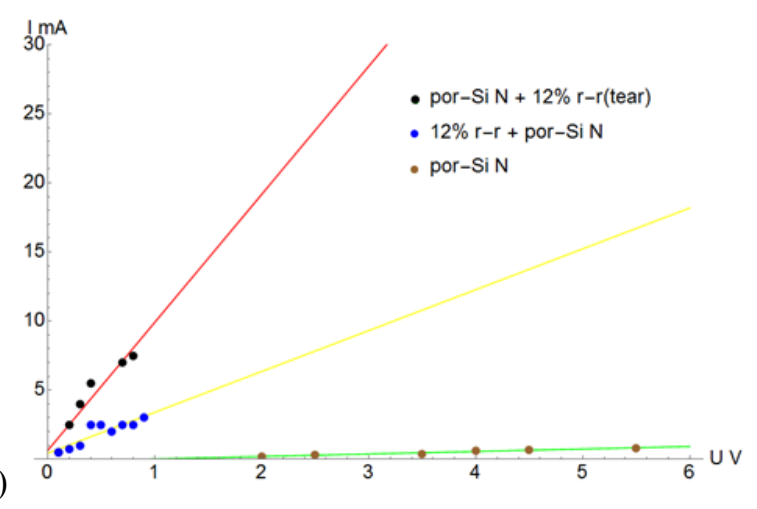

Fig. 5 CVC of a silicon + glucose nanocomposite of the percentage glucose in the tear fluid $(3 \%, 6 \%$, and $12 \%$ glucose). 
Table 3 Dependence of the stability of PC samples on the presence in them of a certain amount of glucose.

\begin{tabular}{|c|c|c|c|c|c|c|}
\hline $\begin{array}{l}\text { Sample number } \\
\text { and glucose } \\
\text { concentration }\end{array}$ & $\begin{array}{c}\mathrm{R} \text { glucose }+ \text { tear } \\
\mathrm{kOhm}\end{array}$ & $\begin{array}{c}\Delta \mathrm{R} / \mathrm{R} \text { glucose }+ \\
\text { tear, } \%\end{array}$ & $\begin{array}{l}\text { R por-Si, } \\
\text { kOhm }\end{array}$ & $\begin{array}{l}\Delta \mathrm{R} / \mathrm{R} \\
\text { por-Si, } \\
\quad \%\end{array}$ & $\begin{array}{c}\text { R glucose } \\
+ \text { tear }+ \\
\text { por-Si, } \\
\text { kOhm }\end{array}$ & $\begin{array}{l}\Delta \mathrm{R} / \mathrm{R} \text { glucose }+ \\
\text { tear }+ \text { por- } \mathrm{Si}, \%\end{array}$ \\
\hline$N(3 \%)$ & 783.45 & 0.3 & \multirow{3}{*}{8737.5} & \multirow{3}{*}{3.5} & 11260 & 4.8 \\
\hline $\mathrm{N}(6 \%)$ & 597.77 & 0.4 & & & 21250 & 5.1 \\
\hline $\mathrm{N}(12 \%)$ & 380.13 & 1.4 & & & 9990 & 3.2 \\
\hline
\end{tabular}

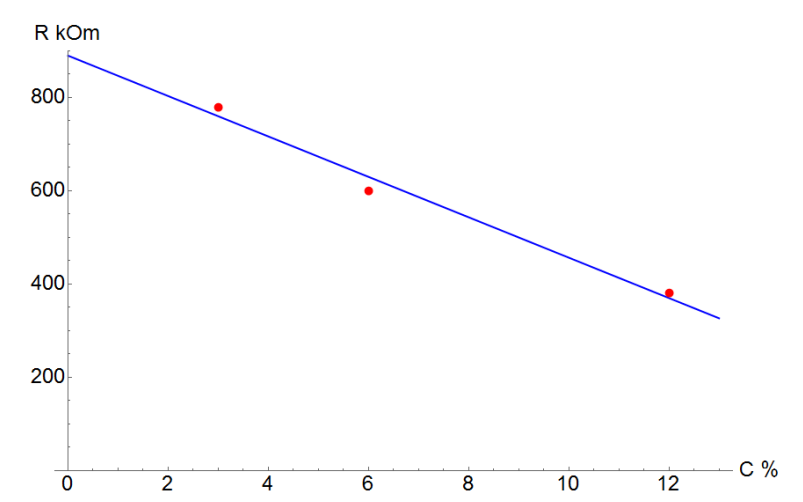

Fig. 6 The dependence of the silicon nanocomposite + glucose resistance on the percentage of glucose in the tear fluid.

Table 4 Calculation of dark characteristics: resistivity and conductivity.

\begin{tabular}{ccc} 
Sample & $\begin{array}{c}\mathrm{p}_{\mathrm{t}}, \text { Ohm per } \\
\text { square }\end{array}$ & $\begin{array}{c}\sigma_{\mathrm{t}}, \mathrm{Om}^{-1} \cdot \text { per } \\
\text { square }\end{array}$ \\
\hline $\mathrm{G}$ & $1.661 \cdot 10^{7}$ & $6.020 \cdot 10^{-8}$ \\
\hline $\mathrm{G}+\mathrm{NaCl}$ & $1.351 \cdot 10^{7}$ & $7.404 \cdot 10^{-8}$ \\
\hline $\begin{array}{c}\mathrm{X}-\text { control } \\
\text { sample }\end{array}$ & $8.365 \cdot 10^{6}$ & $1.196 \cdot 10^{-7}$ \\
\hline $\begin{array}{c}\mathrm{X}+6 \% \\
\text { glucose solution }\end{array}$ & $4.350 \cdot 10^{6}$ & $2.299 \cdot 10^{-7}$ \\
\hline $\begin{array}{c}\mathrm{X}+12 \% \\
\text { glucose solution }\end{array}$ & $4.021 \cdot 10^{6}$ & $2.487 \cdot 10^{-7}$
\end{tabular}

Table 5 Calculation of light characteristics: resistivity and conductivity.

\begin{tabular}{ccc} 
Sample & $\begin{array}{c}\mathrm{p}_{\mathrm{sv}}, \mathrm{Ohm} \cdot \mathrm{per} \\
\text { square }\end{array}$ & $\begin{array}{c}\sigma_{\mathrm{sv}}, \mathrm{Ohm}^{-1} \cdot \mathrm{per} \\
\text { square }\end{array}$ \\
\hline $\mathrm{G}$ & $5.830 \cdot 10^{5}$ & $1.715 \cdot 10^{-6}$ \\
\hline $\mathrm{G}+\mathrm{NaCl}$ & $3.250 \cdot 10^{5}$ & $3.077 \cdot 10^{-6}$ \\
\hline $\begin{array}{c}\mathrm{X}-\text { control } \\
\text { sample }\end{array}$ & $1.239 \cdot 10^{6}$ & $8.070 \cdot 10^{-7}$ \\
\hline $\begin{array}{c}\mathrm{X}+6 \% \text { glucose } \\
\text { solution }\end{array}$ & $4.35 \cdot 10^{5}$ & $2.299 \cdot 10^{-6}$ \\
\hline $\begin{array}{c}\mathrm{X}+12 \% \text { glucose } \\
\text { solution }\end{array}$ & $1.428 \cdot 10^{6}$ & $7.003 \cdot 10^{-7}$
\end{tabular}

As can be seen from the graph in Fig. 6, the resistance of the silicon + glucose nanocomposite depends on the concentration of glucose in the lacrimal fluid. This dependence is rather well approximated by a decreasing linear function. For a nanocomposite with an aqueous glucose solution, the function is also diminishing, although its linearity is not so obvious.

For various samples of porous silicon with various supported substances $(\mathrm{NaCl} ; 6 \%, 12 \%$ glucose solutions), photoconductivity was measured. By measuring the current - voltage characteristics with and without illumination, it is possible to determine the dark $\left(\sigma_{t}\right)$ and light $\left(\sigma_{\mathrm{sv}}\right)$ conductivities of the samples, as well as $\Delta \sigma=\sigma_{\mathrm{t}}(\mathrm{PC})-\sigma_{\mathrm{t}}(\mathrm{PC}+$ substance $), \Delta \sigma / \sigma_{\mathrm{t}}$, and $\Delta \sigma / \sigma_{\mathrm{sv}}$. Fig. 7 shows the I-V characteristics of a nanocomposite with $\mathrm{NaCl}$.

(a)

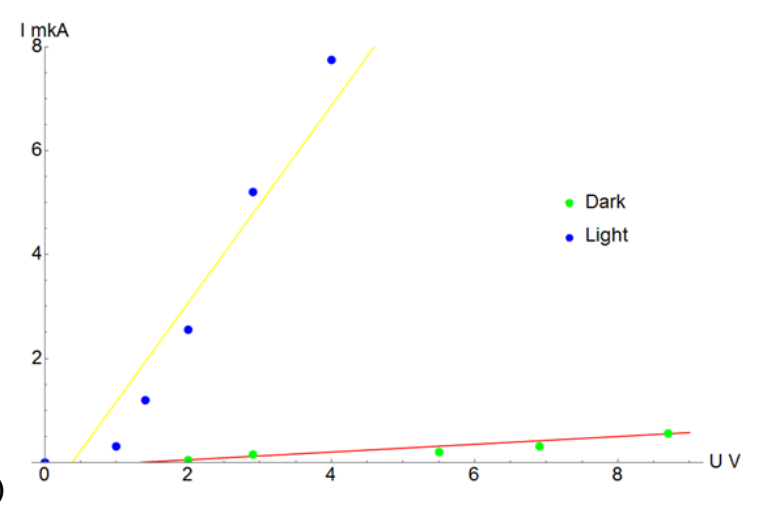

(b)

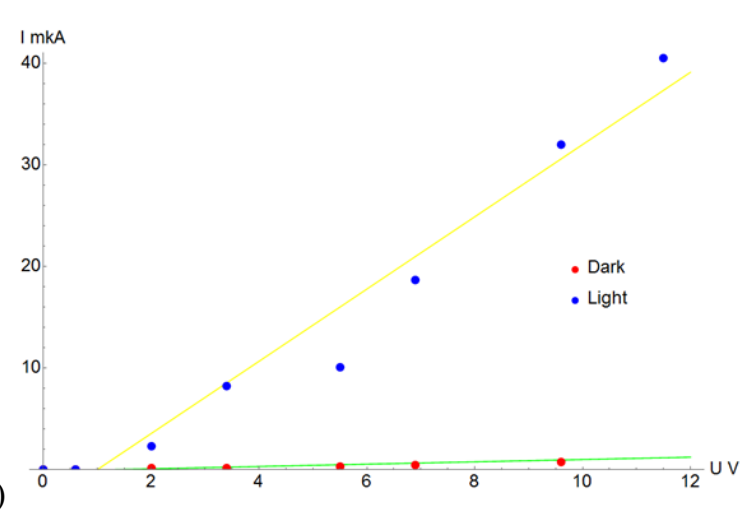

Fig. 7 CVC: (a) sample G-control and (b) sample G + $\mathrm{NaCl}$.

Fig. 8 shows the $\mathrm{I}-\mathrm{V}$ characteristics of a nanocomposite with 6 and $12 \%$ glucose. 


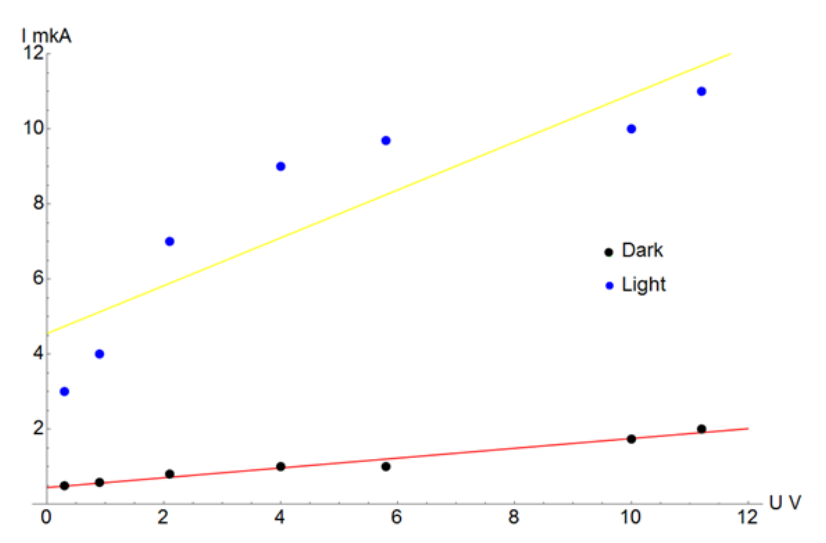

(a)

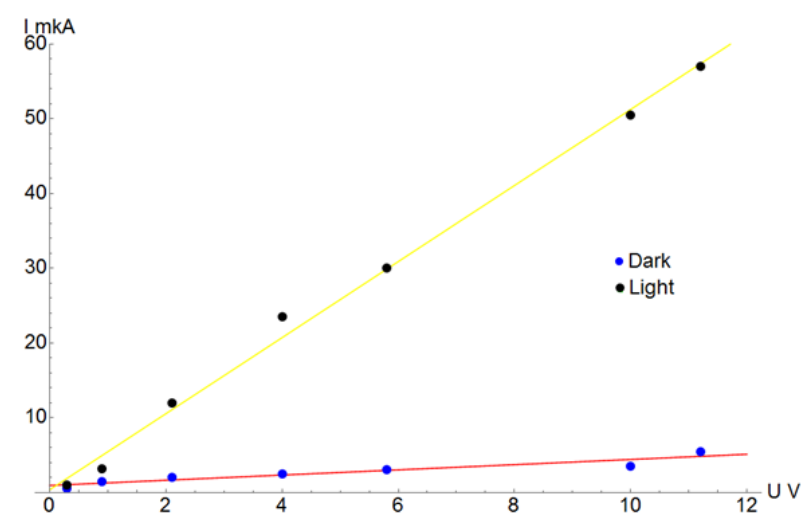

(b)

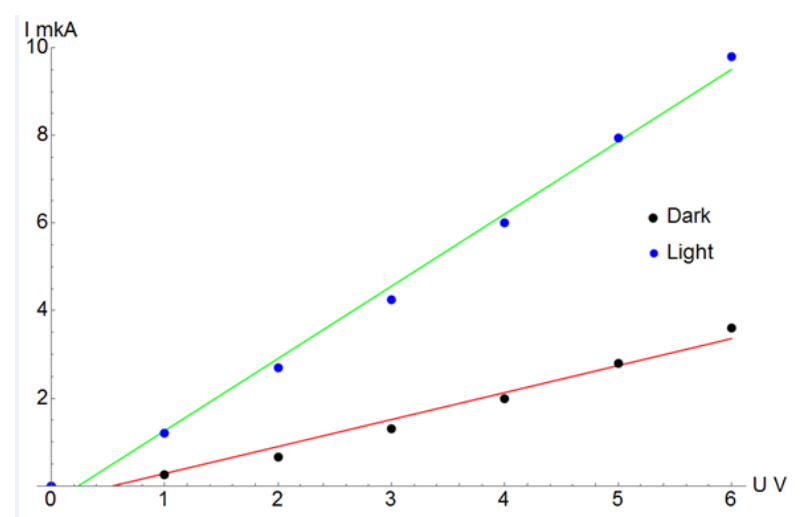

(c)

Fig. 8 CVC: (a) X - control sample, (b) X with glucose of $6 \%$ solution, (c) X with glucose of $12 \%$ solution.
The calculation of resistivity and conductivity is given in Tables 4-5.

The obtained results demonstrate that all plates have high photosensitivity. The presence of glucose on the porous layer shows a significant increase in both dark and light conductivity. The presence of $\mathrm{NaCl}$ in the sample does not significantly change the conductivity; the order remains the same. Calculations of the change in dark conductivity with the addition of substances to the samples are shown in Table 6.

Table 6 Change in dark conductivity with the addition of substances to the samples.

\begin{tabular}{cccc} 
№ sample & $\begin{array}{c}\Delta \sigma / \sigma_{\mathrm{t}}, \\
\%\end{array}$ & $\begin{array}{c}\Delta \sigma / \sigma_{\mathrm{sv}}, \\
\%\end{array}$ & $\begin{array}{c}\text { Amount of } \\
\text { substance }\end{array}$ \\
\hline $\begin{array}{c}\mathrm{G} \text { (with NaCl } \\
\text { solution) }\end{array}$ & 23 & 82 & 0.016 \\
\hline $\begin{array}{c}\mathrm{X} \text { (when adding } \\
6 \% \text { glucose }\end{array}$ & 92 & 188 & 0.323 \\
solution in water) & & 14 & 0.571 \\
\hline $\begin{array}{c}\text { X (when adding } \\
12 \% \text { glucose } \\
\text { solution in water }\end{array}$ & 120 & 14 &
\end{tabular}

\section{Conclusion}

It was found that the resistance of porous silicon varies markedly in the presence of glucose in the pores. With an increase in glucose content, the resistance markedly decreased for all the studied samples with different porosities. Samples with a porous layer made on a polished surface $(\mathrm{N})$ have the highest porosity that is an attractive quality for using such a material in a biosensor. In this case, a nanocomposite with such a surface is characterized by a linear dependence of the resistance on the glucose content in the pores. From this, we can conclude that porous silicon is a promising material for creating an electric or combined opticalelectric glucose biosensor.

\section{Disclosures}

All authors declare that there is no conflict of interests in this paper.

\section{References}

1. A. Samuilkina, "New biosensors measure sugar levels with a few drops of sweat," High-tech, 2016 (accessed 10 august 2019).

2. O. I. Ksenofontova, A. V. Vasin, V. V. Egorov, A. V. Bobyl', F. Y. Soldatenkov, E. I. Terukov, V. P. Ulin, N. V. Ulin, and O. I. Kiselev, "Porous silicon and its applications in biology and medicine," Technical Physics 59(1), 6677 (2014). 
3. N. V. Latukhina, D. A. Lizunkova, I. A. Shishkin, G. A. Rogozhina, and V. A. Gurenkova, "The influence of uncontrolled factors on the properties of porous silicon," Collection of reports of the VIII International Scientific Conference, 63-65 (2018).

4. K. A. Ganichkina, N. V. Latukhina, and D. R. Suyundukova, "Optical methods for studying porous silicon-based biomaterial," Proceeding of XVI All-Russian Youth Samara Competition - a conference of scientific papers on optics and laser physics, 268-276 (2018). [in Russian]

5. Y. Chen, S. Lu, S. Zhang, Y. Li, Z. Qu, Y. Chen, B. Lu, X. Wang, and X. Feng, "Skin-like biosensor system via electrochemical channels for noninvasive blood glucose monitoring," Science advances 3(12), e1701629 (2017).

6. S. Zairi, C. Martelet, N. Jaffrezic-Renault, R. M'gaïeth, H. Maâref, and R. Lamartine, "Porous silicon a transducer material for a high-sensitive (bio) chemical sensor: effect of a porosity, pores morphologies and a large surface area on a sensitivity," Thin Solid Films 383(1-2), 325-327 (2001).

7. W. Y. Tong, M. J. Sweetman, E. R. Marzouk, C. Fraser, T. Kuchel, and N. H. Voelcker, "Towards a subcutaneous optical biosensor based on thermally hydrocarbonised porous silicon," Biomaterials 74, 217-230 (2016).

8. J. Salonen, V. P. Lehto, "Fabrication and chemical surface modification of mesoporous silicon for biomedical applications," Chemical Engineering Journal 137(1), 162-172 (2008). 